\title{
As potencialidades da Literatura de Cordel para o Ensino de Física na perspectiva de professores-pesquisadores da área de Educação em Ciências/Física
}

\section{The potentialities of Cordel Literature for Physics Teaching from the perspective of teacher-researchers in Science Education}

\author{
Wagner José dos Santos (wjs.wagner13@gmail.com) \\ Programa de Pós-graduação em Ensino de Ciências e Matemática - PPGECIM \\ Universidade Federal de Alagoas - UFAL \\ Ivanderson Pereira da Silva (ivanderson@gmail.com) \\ Programa de Pós-graduação em Ensino de Ciências e Matemática - PPGECIM \\ Universidade Federal de Alagoas - UFAL
}

\begin{abstract}
Resumo:
A disciplina "Temas de Física na pesquisa-formação de professores", ofertada pelo Programa de Pós-graduação em Educação em Ciências da Universidade Federal do Rio Grande (PPGEC/FURG), no segundo semestre de 2017, na modalidade online, reuniu 18 pesquisadores em Educação em Ciências/Física oriundos dessa instituição, mas também da Universidade Federal do Pampa e da Universidade Federal de Alagoas. Dentre os temas discutidos ao longo desta experiência destacamos, por sua originalidade, o módulo 4, intitulado "O cordel no Ensino de Física". Dentre as atividades propostas destacamos o fórum de discussão que problematizou o conceito e as potencialidades didáticas da literatura de cordel para o ensino de Física. Em face desse objeto, investigamos os significados que esses sujeitos, atribuíram às potencialidades didáticas da literatura de cordel. Trata-se de um estudo qualitativo, no qual foi realizada a análise textual discursiva das interações que constituíram o fórum de discussão em tela. A partir disso, constatou-se que os sujeitos envolvidos significaram que a produção de cordéis acerca de temas de Ciências/Física é um exercício que exige: a) a compreensão do gênero literário em tela; b) muita criatividade para com ele trabalhar e; c) estudo comprometido acerca do conteúdo científico abordado.
\end{abstract}

Palavras-chave: Análise textual discursiva; Pesquisa-formação; Literatura de Cordel.

\begin{abstract}
:
The discipline "Physics Themes in Research-Teacher Training", offered by the Graduate Program in Science Education at the Federal University of Rio Grande (PPGEC / FURG), in the second semester of 2017, in the online modality, brought together 18 researchers in Science / Physics Education from that institution, but also from the Federal University of Pampa and the Federal University of Alagoas. Among the themes discussed throughout this experience, we highlight, due to its originality, module 4, entitled "The cordel in Physics Teaching". Among the proposed activities we highlight the discussion forum that problematized the concept and the didactic potentialities of cordel literature for teaching Physics. In view of this object, we investigated the meanings that these subjects attributed to the didactic potentialities of
\end{abstract}


cordel literature. It is a qualitative study, in which the discursive textual analysis of the interactions that constituted the discussion forum on screen was carried out. From this, it was found that the subjects involved meant that the production of cordéis on Science / Physics themes is an exercise that requires: a) understanding of the literary genre on screen; b) a lot of creativity to work with him and; c) committed study about the scientific content covered.

Keywords: Discursive textual analysis; Research-training; Literature of Cordel.

\section{INTRODUÇÃO}

A cultura emergente das práticas sociais que exploram as tecnologias digitais da informação e comunicação (TDIC) caracterizam o espaço-tempo em que nos situamos, ou seja, a cibercultura. Lévy (1999) define o termo como um novo universo de informações que abriga os seres humanos em uma forma de comunicação gerada pelas interconexões dos computadores ao redor do mundo. Deste modo, a cibercultura se apresenta como um conjunto de práticas sociais que modifica e é modificada por meio dos processos comunicacionais emergentes da relação entre os sujeitos e o computador conectado à internet.

Esta nova configuração das práticas sociais, propulsionada pelos meios digitais, permitiu a emergência da educação online, compreendida como um fenômeno próprio da cibercultura e que se caracteriza principalmente pela exploração da interatividade e flexibilidade das interfaces de autoria e colaboração disponíveis na internet, com vistas ao desenvolvimento intencional de processos de ensino e aprendizagem (SILVA; SANTOS, 2009; SILVA, 2012; SANTOS, 2014).

Autores como Santos e Silva (2009) consideram que, na sala de aula online, a aprendizagem não está centrada na figura do professor. Esse, deve atuar como um mediador da aprendizagem, encorajador do diálogo, arquiteto de percursos de aprendizagem e mobilizador da inteligência coletiva (SILVA et al., 2009; MASSETO, 2007).

Ao vislumbrar tais possibilidades, em julho de 2017, 18 pesquisadores do campo da Educação em Ciências se articularam na construção da disciplina online intitulada “Temas de Física na Pesquisa-formação de professores”. Esse componente curricular foi 
ofertado pelo Programa de Pós-graduação em Educação em Ciências (PPGEC) da Universidade Federal do Rio Grande (FURG).

Participaram desta experiência professores do curso de Licenciatura em Física da Universidade Federal do Pampa (UNIPAMPA); professores e estudantes do curso de Licenciatura em Física e do Mestrado do Programa de Pós-graduação em Ensino de Ciências e Matemática (PPGECIM) da Universidade Federal de Alagoas (UFAL); bem professores e estudantes do Mestrado e do Doutorado em Educação em Ciências do PPGEC/FURG.

O planejamento desta disciplina foi estruturado inicialmente em 15 semanas. A primeira semana se voltou para a ambientação dos participantes entre si e com o ambiente virtual de aprendizagem (AVA) Moodle da FURG < http://www.moodle.sead.furg.br/>, no qual as atividades foram desenvolvidas.

Na sequência, a cada duas semanas, um grupo de até 3 (três) participantes se responsabilizou pelo planejamento pedagógico, a elaboração do material didático e a condução da docência online de um módulo curricular. Cada módulo curricular deveria eleger como foco a exploração de um tema de Física. Foram compostos 5 (cinco) módulos.

Dentre os temas discutidos ao longo desta experiência destacamos, por sua originalidade, o módulo 4 intitulado "O cordel no Ensino de Física". Esse módulo, assim como os demais, teve duas semanas de duração. Dentre as atividades propostas destacamos o fórum de discussão que problematizou o conceito e as potencialidades didáticas da literatura de cordel para o ensino de Física.

Assim, o presente estudo investigou a seguinte questão: como os pesquisadores da área de ensino de Ciências/Física, envolvidos na disciplina "Temas de física na pesquisa-formação de professores", significaram as potencialidades didáticas da literatura de cordel?

Em face dessa questão, esse estudo teve por objetivos: analisar os diálogos produzidos no interior do fórum de discussão Cordel no ensino de física; e identificar como os participantes dessa experiência significaram o conceito e as potencialidades didáticas da literatura de cordel. 
O relato dessa pesquisa está descrito nas próximas sessões conforme a seguinte sequência: num primeiro momento discutimos acerca das bases teóricas da educação em Ciências no contexto da cibercultura; em continuidade apresentamos os procedimentos metodológicos desta pesquisa; e por fim os resultados e discussões que favoreceram o apontamento de respostas ao problema que mobilizou essa investigação.

\section{A LITERATURA DE CORDEL E A EDUCAÇÃO EM CIÊNCIAS}

Historicamente o "cordel" surgiu a partir dos romanceiros luso-holandeses da Idade Contemporânea e do Renascimento. A forma como são nominados os folhetos com poemas populares decorre do modo como eram vendidos (pendurados em cordas) (LUYTEN, 2005). No Brasil acredita-se que tal gênero literário apareceu por volta do século XVIII, trazido pelos portugueses. Dentre os cenários em os cordéis mais se difundiram, destaca-se a região do nordeste brasileiro. A diversidade cultural desta região permitiu que os cordelistas retratassem os atores sociais, sua historicidade, língua, espaços e tempos em texto e imagem.

Apesar de o título de primeiro cordelista ainda ser disputado, de acordo com Terra (1983), Leandro Gomes de Barros foi o primeiro poeta a imprimir os folhetos regularmente e comercializá-los pelas ruas de Recife-PE no percurso do trem da linhasul de Pernambuco. Porém o termo "literatura de cordel" foi utilizando pela primeira vez por Silvio Romero, informando que esse gênero apresenta características próprias, como sua estrutura em versos, a métrica quanto às rimas e a forma do texto.

Nesse sentido, Assis et al. (2013) comentam que, dentre algumas características dos folhetos de cordel estão: a padronização do tamanho $(11$ x 15,5 cm), a ilustração (geralmente em xilogravura), o humor peculiar e a linguagem popular. Além disso, esse material impresso possui uma variedade de enredos nos quais se abordam dramas, sátiras, críticas sociais e acontecimentos diversos. Dentro dessa estrutura, Araújo (2009) considera que, por meio dos folhetos, a literatura de cordel propaga saberes que são frutos da realidade social vivida pelo poeta. Tais escritos transformam-se em memória, documento e registro da história, valorando a identidade local e as tradições regionais de uma determinada comunidade. 
Em face de seu potencial pedagógico, professores têm explorado esse material em contextos variados de ensino e aprendizagem. Segundo Lacerda e Menezes Neto (2010, p. 226) "o cordel é um recurso que não apresenta grandes dificuldades de compreensão para os alunos, já que a sua linguagem é em forma de versos rimados". Autores como Lima et al. (2012, p. 9) consideram que o uso do cordel em aulas de Ciências, por exemplo, "torna o seu cotidiano mais próximo do conhecimento científico, proporcionando um relacionamento mais simples da ciência com o dia a dia". Observase, nesse sentido, que os cordéis podem ser explorados com vistas ao ensino, à divulgação e à popularização da Ciência.

\section{PROCEDIMENTOS METODOLÓGICOS}

Em face das características dos cordéis, envidamos esforços em analisar as concepções de um grupo de pesquisadores em Educação em Ciências, acerca do que significavam sobre as potencialidades didáticas desse gênero literário. Trata-se de uma investigação e do tipo exploratória, de natureza qualitativa, pois será aplicada no ambiente natural e cotidiano dos participantes (MORAES, 2002; SAMPIERI, COLLADO; LÚCIO, 2013). Tal estudo contou com a participação de 18 sujeitos.

O quadro 1 apresenta a distribuição dos sujeitos de pesquisa de acordo com as instituições às quais pertenciam e também de acordo com o nível acadêmico que ocupavam no contexto o espaço-tempo em que esse estudo foi desenvolvido.

Quadro 1 - Sujeitos da pesquisa

\begin{tabular}{|l|l|c|}
\hline Instituição & \multicolumn{1}{|c|}{ Sujeitos } & Quantitativo \\
\hline \multirow{2}{*}{ FURG } & Mestrandos / Mestrandas do PPGEC/FURG & 8 \\
\cline { 2 - 3 } & Doutorandos / Doutorandas do PPGEC/FURG & 2 \\
\cline { 2 - 3 } & $\begin{array}{l}\text { Professores Universitários / Professoras Universitárias } \\
\text { do PPGEC/FURG }\end{array}$ & 1 \\
\hline UNIPAMPA & $\begin{array}{l}\text { Professores Universitários / Professoras Universitárias } \\
\text { da UNIPAMPA }\end{array}$ & 2 \\
\hline UFAL & Estudantes de Graduação do curso de Licenciatura em & 1 \\
\hline
\end{tabular}




\begin{tabular}{|l|l|c|}
\hline & Física (Iniciação Científica) & \\
\cline { 2 - 3 } & Mestrandos / Mestrandas do PPGECIM/UFAL & 4 \\
\cline { 2 - 3 } & Professor Universitário & 2 \\
\hline
\end{tabular}

Fonte: Os autores

A demanda por essa experiência emergiu inicialmente das relações de colaboração entre esse grupo de pesquisadores que, à distância, vinham experimentando possibilidades de ensino e de pesquisa acerca de temas de Física mediados por interfaces da internet.

Em face do delineamento dessa rede de pesquisadores, os professores universitários envolvidos decidiram organizar essa experiência e envolver nela alguns de seus orientandos de iniciação científica, de mestrado e de doutorado. Aqueles e aquelas que voluntariamente concordaram em participar da experiência, compuseram esse grupo.

O contexto da pesquisa foi o módulo 4 da disciplina "Temas de Física na pesquisa-formação de professores”. Esse, enfocou “O cordel no ensino de Física”. Tal módulo apresentou a literatura de cordel como recurso didático no ensino de Ciências/Física. O mural principal, ilustrado na figura 1, favorece a visualização do desenho didático proposto nesse módulo.

Nesse mural inicial foram disponibilizados o plano do módulo (no qual constavam a ementa, os objetivos, os conteúdos, a metodologia proposta, a estratégia de avaliação da aprendizagem e as referências utilizadas); vídeos de curta duração, por meio dos quais o grupo responsável pela autoria desse módulo se apresentava aos demais participantes; e duas atividades que aconteciam concomitantemente.

A primeira atividade consistia no fórum de discussão intitulado "O Cordel no ensino de Física". Para subsidiar o debate neste fórum, disponibilizamos um material de apoio. Esse material discutia sobre a variedade de materiais impressos que podem apoiar a prática dos professores de Ciências; definia o conceito e as potencialidades didáticas da literatura de cordel; orientava acerca dos tipos de cordéis e como construir 
cordéis; e apresentava exemplos de diferentes tipos de cordéis com foco em temas de Física.

A segunda atividade desafiou os participantes a produzirem seus próprios cordéis a partir de temas de Física que poderiam ser escolhidos livremente. Participaram como cursistas deste módulo, os autores do módulo (3 participantes) e mais 14 participantes (que foram autores de outros módulos). 
Oitava e Nova Semana (09 a 22 de novembro de 2017)
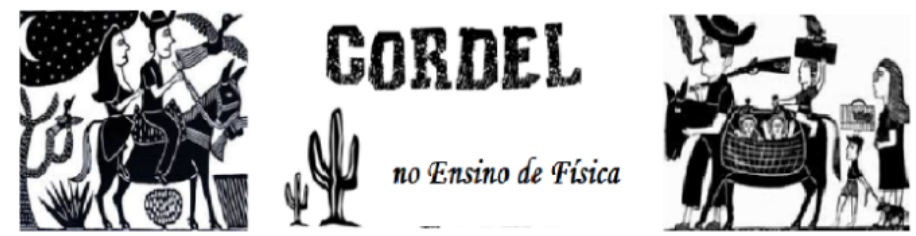

Saudaçōes nobres colegas da disciplina "Temas de Física na Pesquisa-formação de Professores"!

Neste módulo enfocaremos o debate acerca do uso da Literatura de Cordel no Ensino de Ciências/Física.

Tal debate tem por objetivos favorecer a compreensão do conceito de cordel, sua construção histórica e classificação; bem como possibilitar a exploração de cordéis produzidos com vistas a apoiar a prática pedagógica em Física e desafiá-l@s a produzir um cordel que enfoque um tema de Fisica.

Para isso, Ihe convidamos a discutir conosco sobre o conceito de cordel e sua classificação no Fórum intitulado "O Cordel no Ensino de Física".

Em seguida, propomos a construção do seu próprio cordel problematizando um tema de Física de sua escolha.

O cordel produzido deve ser postado na Tarefa intitulada "Produzindo um cordel com um tema de Fisica".

Essas duas atividades deverão ser realizadas no período de 09 a 22 de novembro de 2017

Convidamos vocês a navegarem nas consignas das atividades.

Vamos lá?

面 Plano do módulo

D) Apresentação

(1) Apresentação

Apresentação

Atividade 1 (09 a 22 de novembro de 2017)

仙 Texto 1 - Potencialidades didáticas da literatura de cordel para o ensino de física

屏 0 cordel no ensino de física

Atividade 2 (09 a 22 de novembro de 2017)

蝞Fórum de dúvidas

Produzindo um cordel com um tema de Física

征 Crie um tópico e Poste aqui o seu Cordel

Espaço reservado para Vídeos

Material Complementar

A Cordel animado (online) 1 - videocordel

- Cordel animado 2 (online) - Cordel em Libras

Q. 9000 cordéis disponíveis online

Artigo 1 (cordel digital)

Figura 1 - Mural principal do módulo, captura de tela / Dos próprios autores 
Como produtos, foram gerados 14 cordéis com temas de Física. Esse material está disponível a partir do endereço eletrônico <http://encurtador.com.br/LNQ38>. Na medida em que esses participantes eram desafiados a produzirem seus cordéis, eram também desafiados a refletirem acerca do conceito e das potencialidades didáticas desse gênero literário. A temática proposta foi debatida por meio de um fórum de discussão (Atividade 1).

O lócus da coleta de dados foi o fórum online intitulado Cordel no ensino de Física, desenvolvido no módulo 4 de mesmo título. O debate nos fóruns, geralmente se inicia a partir de uma consigna com questões instigantes que provoquem os participantes a discutirem sobre o tema proposto. Silva et al. (2009) apontam que a preparação antecipada dos alunos é imprescindível para a interação no fórum, para que suas colocações não sejam meramente concordar ou discordar das postagens escritas posteriormente. Esses participantes precisam estar abertos a novos posicionamentos e terem disposição para compartilhar experiências com os demais.

Os registros das contribuições dos participantes continham o potencial de explicitar como os participantes dessa experiência significaram o conceito e as potencialidades didáticas da literatura de cordel. Desta forma, os fóruns ao mesmo tempo em que favorecem diálogos formativos, se constituem em importantes recursos de coleta e análise de dados para pesquisa (LIMA; HAGUENAUER, 2014).

A consigna do fórum "O cordel no ensino de Física", continha informações sobre sua proposta, uma sugestão de texto para fundamentar o debate, três questões norteadoras e um convite ao debate. A consigna pode ser visualizada a partir da figura 2.

O fórum intitulado "O cordel no ensino de Física", registrou 62 contribuições. Participaram desse fórum, 17 participantes. Desse modo, analisar as interações num fórum pode contribuir para identificar diferentes pontos de vista sobre um tema especifico. Nesse sentido, a partir do instrumento analítico da ATD, investigamos os diálogos produzidos no interior do fórum de discussão. 


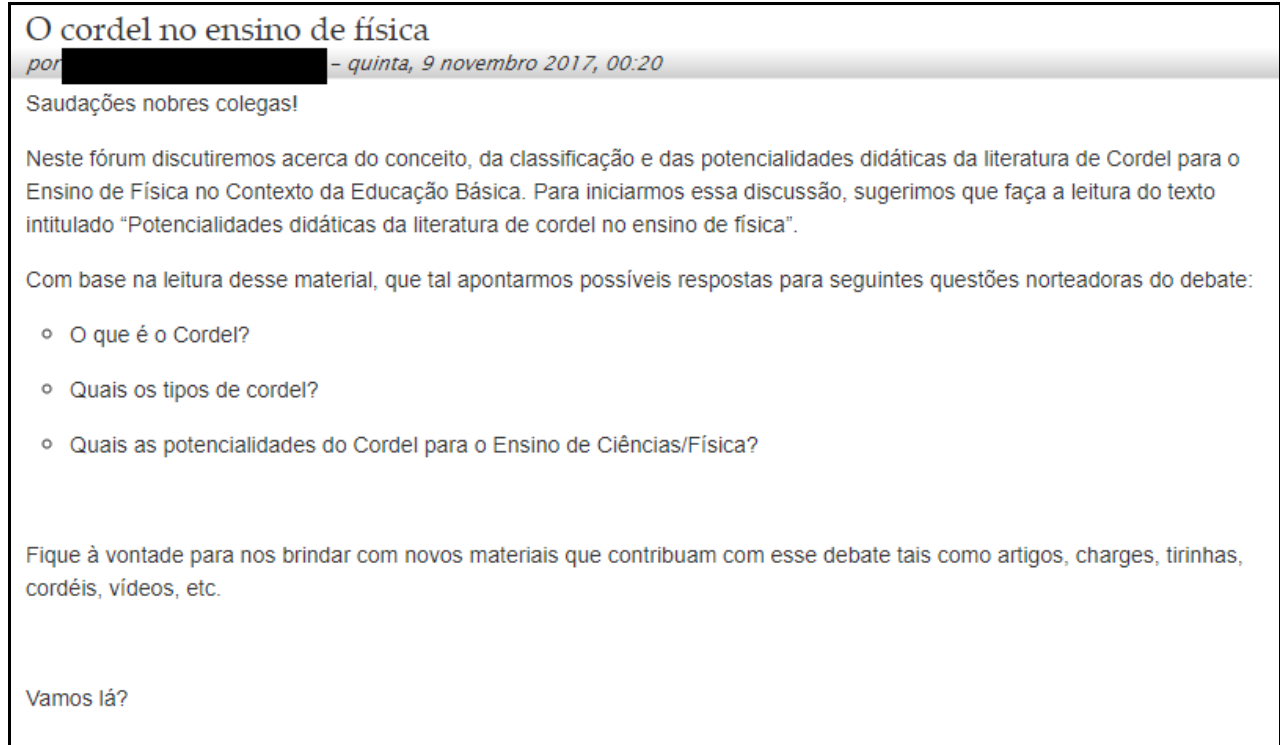

Figura 2 - Consigna do Fórum, captura de tela / Do próprio autor

A proposição da pesquisa como eixo dos processos de formação dos professores não é uma novidade (GALIAZZI, 2011). Para Longarezi et al. (2007) o processo de formação provocado pela pesquisa deve enfocar a consciência crítica, o questionamento, a capacidade de intervenção e a consolidação da unidade teoria-prática (PIMENTA; LIMA, 2004).

Embora seja reconhecida a pesquisa como estratégia da formação docente, sua integração ao trabalho pedagógico tem sido uma tarefa árdua (RAUSCH, 2012). Nesse sentido, a pesquisa-formação surge como uma alternativa teórico-metodológica para a formação profissional docente e ao mesmo tempo para as práticas pedagógicas desses sujeitos.

Assim, os envolvidos investigam situações problemas que emergiram de suas experiências imediatas, ou das experiências de seus pares, e buscaram construir respostas para as questões levantadas (LONGAREZI; SILVA, 2013). Nesse cenário, os sujeitos buscaram mudanças em suas práticas a partir das experiências vividas e das investigações desenvolvidas. O participante ocupou o lugar, simultaneamente, de objeto e de sujeito da formação e da investigação. 
Para Perrelli et al. (2013) a pesquisa-formação ao invés de distanciar-se do fenômeno, na tentativa de controlar e explicá-lo, procura construir significados e sentidos, formar e transformar-se durante a ação da pesquisa-intervenção. A pesquisaformação reconhece que não se deve olhar o fenômeno pelo lado de fora, as investigações compõem um ambiente de formação e autoformação em que riscos e incertezas fazem parte do processo de constituição do professor-pesquisador.

Na pesquisa-formação, o sujeito constrói (con)juntamente com outros, buscando a produção de conhecimento e a reformulação de suas práticas. Isso implica, no contexto da pesquisa e da prática pedagógica, que o professor-pesquisador produza conhecimento a partir dos problemas vivenciados na ação docente. Segundo Santos e Silva (2019, p. 206), do ponto de vista metodológico, a pesquisa-formação, no contexto da educação online pode se configurar a partir da

[...] organização de grupos que alternam de forma sistemática os papéis, docente e discente a partir do seguinte esquema: Inicialmente um grupo assume a docência enquanto os demais grupos ocupam a função de alunos. Ao concluir sua intervenção, esse primeiro grupo que assumiu a docência, passa a ocupar o lugar de alunos e um segundo grupo assume a docência. A partir das experiências vivenciadas pelos sujeitos, emergem questões de pesquisa as quais podem ser exploradas na perspectiva da reflexão-ação, de seus percursos, ou dos percursos de seus pares

Diante das potencialidades do ciberespaço e, de modo específico as potencialidades do AVA Moodle, estruturamos o componente curricular "Temas de Física na pesquisa-formação de professores" a partir dessa abordagem metodológica.

$\mathrm{Na}$ perspectiva da pesquisa-formação, os grupos se alternaram na condução da exploração de temas de Física da seguinte forma: na medida em que o grupo 1 assumiu a docência, os demais grupos ocuparam a função discente. Ao concluir sua intervenção, o grupo 1 cedeu o lugar da docência ao grupo 2 e junto com os demais ocuparam a função discente; e assim sucessivamente. Desse modo, todos os participantes se envolveram nas ações coletivas dos temas desenvolvidos ocupando as funções da docência e da discência online.

O processo metodológico para a análise e interpretação dos dados foi a Análise Textual Discursiva (ATD). A ATD considerou três fases (MORAES; GALIAZZI, 2013, p. 11): "a desmontagem do texto ou unitarização, [...] [que] consiste em examinar os 
detalhes do texto, fragmentá-lo e dividi-lo unidades constituintes"; a categorização, na qual se busca "reunir os elementos unitários na formação de conjuntos de elementos próximos" (idem); e por fim, a "captação do novo emergente, do resultado das fases anteriores, [que] possibilita uma nova compreensão do objeto de pesquisa" (idem). A captação do novo emergente foi desenvolvida a partir da criação de metatextos que resultaram da sistematização recursiva das unidades de significado fragmentadas e reunidas pelos autores dessa investigação.

Os cuidados éticos foram tomados ao longo do estudo e para que o material gerado ao longo dessa experiência pudesse ser utilizado para fins de pesquisa, todos os sujeitos envolvidos assinaram Termo de Consentimento Livre Esclarecido (TCLE) que se encontra em pasta compartilhada no Google Drive e sob a guarda dos coordenadores dessa investigação.

A ATD é entendida como uma abordagem de análise de dados qualitativos, idealizada por Moraes e Galiazzi (2013), que transita entre a análise de conteúdo e a análise de discurso. Esses autores organizaram a ATD em três etapas principais: a) desmontagem dos textos; b) estabelecimento de relações; c) captação do novo emergente. A desmontagem de textos é também compreendida como o momento da unitarização, ou fragmentação do texto. Nessa etapa o analista busca as unidades de significado e as codifica, classificando-as de acordo com os sentidos produzidos. Após essa etapa de fragmentação e de codificação, o analista passa a estabelecer relações entre as unidades de significado que produziram sentidos em torno de um mesmo objeto. Esse segundo movimento favorece a emergência de categorias.

Além de estabelecerem relações entre si, esses fragmentos podem também estabelecer relações com argumentos de outros autores ou com resultados de pesquisas que favoreçam uma compreensão aprofundada do objeto em torno do qual emergiram as categorias. Nesse sentido, a desmontagem dos textos está para a unitarização assim como o estabelecimento de relações está para a categorização dos dados. Esse movimento de diálogo entre as unidades de significado e delas com argumentos de outros autores ou com resultados de pesquisas, se constitui num movimento recursivo por meio do qual novos sentidos são produzidos pela inferência do analista. O produto 
desse movimento recursivo é um metatexto. Segundo Moraes (2003, p. 192) "o metatexto resultante desse processo representa um esforço em explicitar a compreensão que se apresenta como produto de uma nova combinação dos elementos construídos ao longo dos passos anteriores". Segundo Moraes e Galiazzi (2013), as categorias podem surgir antes da análise dos dados (categorias a priori) ou ao longo da análise dos dados (categorias emergentes).

Para este trabalho, os participantes da pesquisa foram designados P1 (Participante 1), P2 (Participante 2), e assim por diante. Com isso, buscou-se preservar a fidelidade autoral dos fragmentos usados e ao mesmo tempo resguardar a identidade desses interlocutores.

As postagens dos participantes no fórum foram fragmentadas e, ao reorganizar os fragmentos, esse movimento possibilitou reuni-los em torno de três categorias emergentes: a) Experiências e práticas dos participantes sobre o cordel; b) Reflexões sobre as potencialidades do cordel no ensino de Ciências/Física; c) Estimulo da aprendizagem colaborativa e participativa. Após o processo de fragmentação unitarização e categorização dos dados, construiu-se um metatexto com todas as categorias, no intuito evidenciar as significações dos participantes acerca do conceito e das potencialidades didáticas da literatura de cordel. A próxima seção apresenta esses metatextos.

\section{METATEXTOS PRODUZIDOS}

Aqui apresentamos os produtos da ATD das produções dialógicas dos sujeitos da pesquisa no fórum intitulado "O cordel no ensino de Física". Esse fórum aconteceu no módulo 4 da disciplina "Temas de Física na pesquisa-formação de professores" e enfocou a literatura de cordel como recurso didático no ensino de Ciências/Física.

A partir da ATD apresentamos as concepções desses pesquisadores em Educação em Ciências acerca das potencialidades didáticas desse gênero literário. $\mathrm{O}$ conteúdo do fórum foi unitarizado e organizado em três categorias: a) Experiências e práticas dos participantes sobre o cordel; b) Reflexões sobre as potencialidades do cordel no ensino de Ciências/Física; c) Estimulo da aprendizagem colaborativa e 
participativa. O material categorizado, a partir do diálogo entre suas unidades de significado, favoreceu a construção dos metatextos que apresentamos a seguir.

\section{a) Experiências e práticas dos participantes sobre o cordel}

Ao introduzir a temática do cordel, buscou-se inicialmente discutir as definições possíveis para esse conceito. Percebemos que, nesse curso de formação de professores de Física, haviam vários participantes que "não conhecia[m] sobre o assunto, pois 'o cordel é bastante utilizado mais para a região do Nordeste"” (P13). Participaram dessa experiência, participantes oriundos dos municípios do Rio Grande (RS), Maceió (AL), Coité do Nóia (AL), Arapiraca (AL), Candiota (RS) e dois participantes da Venezuela. Para os participantes que vivem fora do Nordeste brasileiro, a literatura de cordel apresentava aspectos culturais diferentes daqueles que estavam habituados e ao mesmo tempo uma oportunidade para troca de informações sobre semelhanças e diferenças dos produtos culturais e da própria cultura dessas regiões.

A discussão sobre a literatura de cordel permitiu aos participantes identificarem as particularidades desse tipo de recurso, além de refletir sobre seu potencial didático no ensino de ciências. Isso pode ser verificado a partir do comentário de P7: "confesso que também não imaginei que através do cordel tinha todas essas propriedades, além de tratar da valorização cultural, poderíamos usar como alternativa didática e ainda mais, no Ensino de Ciências". O que se evidencia é que "a linguagem escrita dos professores é mediadora das experiências das investigações comunicadas, uma vez que é por intermédio dela que emergem os sentidos e construímos/ampliamos significados" (GUIDOTTI; HECKLER, 2019, p. 124).

Em função de significarem tal recurso como uma novidade, os desafios propostos nesse módulo foram vistos pelos participantes como "uma tarefa desafiadora usar o Cordel como 'uma alternativa no ensino, e sendo temas científicos, isso torna mais desafiador ainda" (P7). Além disso, seu uso "exige bastante criatividade e domínio do conteúdo para que o cordel faça sentido" (P11). Apesar de desafiador, os participantes significaram tal recurso como um valoroso instrumento para o ensino de Ciências. Além disso, P6 enxergou nesse recurso "uma boa dica para a gente que está 
aprendendo uma nova língua" (P6). Sendo venezuelano, P6 encontrou no cordel uma oportunidade para melhorar o aprendizado da língua portuguesa.

O texto disponibilizado pelos proponentes do módulo foi um primeiro contato dos participantes não-nordestinos com o tema. Os participantes ao lerem esse texto, sentiram a "necessidade de procurar mais informações acerca da referida literatura" (P4). No contexto da educação online, os participantes não se limitam ao material disponibilizado no AVA, pois buscam serem participantes ativos e consequentemente autônomos na busca por mais e melhores referências para si e as compartilham com seus pares.

Já nas primeiras discussões do fórum observou-se esse movimento de compartilhamento de novos materiais (textos e vídeos) que apresentavam contribuições relevantes para a ampliação da compreensão do tema discutido. Isso permitiu a alguns participantes aprofundarem sua percepção acerca do que é cordel: "confesso que a princípio não sabia como colaborar com o tema [...]. Mas lendo as interações dos colegas $[\ldots]$ acabei me encantando por essa alternativa" (P12).

\section{b) Reflexões sobre as potencialidades do cordel no ensino de Ciências}

Ao serem questionados acerca das potencialidades do cordel no ensino de Ciências/Física os participantes apontaram inicialmente que "os conhecimentos científicos podem ser explorados a partir do viés da contextualização" (P8). Nesse cenário, os temas da ciência são tratados levando em conta aspectos da vida cotidiana dos participantes. Isso permite que a aprendizagem não esteja desvinculada da realidade por ele vivida, assumindo o papel de crítico diante de questões sociais e científicas.

Para P4, "os folhetos de cordel, podem oportunizar a construção de conhecimentos Físicos, nesse sentido, a linguagem emerge com ferramenta cultural que além de viabilizar a intenção entre os sujeitos, oportuniza a construção, expressão e explicitação dos 'novos' conhecimentos" (P4). Desta forma, é perceptível que esses participantes conseguiram significar a literatura de cordel como recursos didáticos que podem apresentar significativos ganhos para o ensino e a aprendizagem de Ciências/Física, seja pelo uso da linguagem, ou da forma com se abordam os temas nos 
cordéis. As contribuições dos participantes sobre esse questionamento ampliaram as ideias sobre como o cordel pode potencializar uma aula de Ciências. Mesmo participantes que desconheciam tal gênero conseguiram identificar suas contribuições em sala de aula, percebendo que "estratégias de ensino que sejam baseadas na criatividade e que fazem o estudante pensar e que trabalhem o lúdico" (P13), tornam-se recursos de grande potencial didático.

Outro aspecto da literatura de cordel, destacado por P7, foi a "peculiaridade de fascinar quem ler, podendo provocar sentimentos em relação a mensagem que se quer passar (P7). Isso se deve por seus versos proporcionarem debates sobre raízes históricoculturais que tanto despertam o interesse e possibilita reflexões relevantes (MOREIRA et al, 2005). Dessa maneira, a temática do cordel traz para o ambiente escolar uma riqueza cultural única. P11, complementa essa consideração ao fazer a seguinte afirmação: "acredito que o uso da poesia em sala de aula, seria a forma de potencializar a reflexão/discussão em coletivo, até mesmo como os cordéis, exigindo dos alunos o envolvimento nessa construção" (P11). Isso permite aos estudantes, o despertar do senso crítico, bem como da capacidade de observar a realidade social, histórica, política e econômica em que vivem. Assim, o trabalho com a literatura de cordel no ensino de Ciências/Física é um "desafio instigante" (P14). Visto que, busca a compreensão de forma lúdica do conhecimento científico integrando-o ao conhecimento popular.

\section{c) Estimulo da aprendizagem colaborativa e participativa}

O fórum pode ser visto como um espaço para que todos os que dele fazem parte se posicionem de forma colaborativa e participativa. Seja compartilhando informações ou aprofundando uma discussão iniciada por um dos participantes. No fórum "O cordel no ensino de Física" observou-se que seus participantes contribuíram de diversas formas, seja recomendando novos materiais que pudessem enriquecer as discussões ou apresentando reflexões sobre os questionamentos feitos durante o debate.

P5 comentou: "deixo o link de um artigo e uma tese de doutorado que encontrei em minhas pesquisas sobre o cordel, o qual achei bem legal" (P5). Como relata Silva et al. (2009), as comunidades, como o fórum, são espaços de aprendizagem colaborativas e 
cooperativas entre os membros de um grupo de discussão e, nesse sentido, todos os participantes devem contribuir para que os diálogos sejam fomentados e para o enriquecimento do material didático do curso, seja por meio de suas contribuições autorais, pela indicação de referências, ou pela socialização de materiais recuperados de repositórios online.

Essa posição favorece que os demais participantes possam mais e melhor aprender acerca do tema em foco, como bem se evidencia na fala de P14: "Estou aqui interagindo com a proposta, leitura dos materiais escritos, vídeos de apresentação e pensando muito a partir dos comentários de cada colega” (P14). Esse participante reforça em sua fala que as contribuições são importantes para criar um pensamento reflexivo sobre o tema e também contribuir para a interação do fórum. Nesse sentido, Lima e Haguenauer (2014) comentam que, as práticas pedagógicas em ambientes virtuais, como o fórum, não devem se limitar ao recebimento passivo das informações, típico das aulas tradicionais.

Uma das etapas do módulo 4 da disciplina "Temas de Física na pesquisaformação de professores" consistiu em desafiar os participantes a construírem individualmente, mas na interlocução com os colegas, um cordel que abordasse um tema de Física. Essa produção, ao ser concluída, deveria ser postada numa interface "Tarefa", que não permite uma troca tão intensa como um fórum. Acerca desse desafio, P14 fez a seguinte sugestão: "E que tal nosso cordel final não ser um arquivo fechado enviado pelo sistema de Tarefa? Pois poderia ser em Fórum Aberto, para podemos interagir no Varal coletivo da nossa sala de aula?" (P14). Desta forma, a fala do participante deixa claro que trazer informações para que todos tenham acesso proporciona a interação no fórum, pois incentiva a cooperação e facilita o aprendizado coletivo e a participação constante dos alunos.

\section{CONSIDERAÇÕES FINAIS}

A partir dos metatextos o que se pode observar é que, os sujeitos envolvidos significaram que a produção de cordéis acerca de temas de Ciências/Física é um exercício que exige: a) a compreensão do gênero literário em tela; b) muita criatividade 
para com ele trabalhar e; c) estudo comprometido acerca do conteúdo científico abordado.

Esses sujeitos apontaram ainda que o uso ou a produção de folhetos de cordel com temas de Ciências/Física pode ser utilizado para favorecer o aprendizado de uma nova língua; para a contextualização de temas de Ciências/Física; para a aproximação da linguagem científica com a linguagem popular; para mobilizar o sujeito para além da razão e atingi-lo em suas emoções por meio dos poemas populares; para favorecer o trabalho colaborativo seja na produção ou na análise dos cordéis.

Além disso, o fato da construção dos cordéis ter se dado a partir da mediação da interface online do Fórum de Discussão, favoreceu a colaboração entre os pares. Nesse sentido, os sujeitos pesquisaram sobre o tema e seus achados foram socializados no Fórum, constituindo assim uma comunidade online na qual todos estavam dispostos a contribuir a serem corresponsáveis pela aprendizagem uns dos outros. Os sujeitos estavam ali para contribuir com seus pares e para aprender juntos.

A análise dessa experiência ratifica que a educação online se apresenta com alto potencial para superação dos paradigmas comunicacionais classicamente estabelecidos no contexto da sala de aula presencial (comunicação um-todos) em favor se uma sala aula interativa (comunicação todos-todos). No entanto, é fundamental que se continue a perseguir mais e melhores alternativas teórico-metodológicas, cada vez mais sólidas, que favoreçam experiências significativas de pesquisa-formação.

Vale ressaltar que o envolvimento e a intensa colaboração dos participantes no interior do fórum analisado permitiram o alargamento e o aprofundamento dos saberes pedagógicos e culturais por meio da interatividade, característica marcante da experiência de pesquisa-formação desenvolvida no cenário da educação online. Esse fórum se constituiu num espaço de trocas no qual os participantes se sentiam livres para atuar como aquilo que são: professores de Ciências/Física, por suas formações acadêmicas, e eternos aprendizes por sua condição humana. Foi por meio dessa troca intensa que as distâncias entre o nordeste brasileiro e o extremo sul do país, se encurtaram. 
A geografia não foi uma barreira para que a comunicação e colaboração entre os participantes favorecessem a troca de saberes e a significação do "cordel como parte da cultura, mas não só do Nordeste" (P16) e sim, de todo o Brasil.

Que usos podem ser realizados nas salas de aula da educação básica e superior (presencial, híbrida e online) dos cordéis produzidos nessa experiência de pesquisaformação? Essa é uma questão que sistematiza um conjunto de indagações que lançamos como desafio para novas e futuras experiências de pesquisas-formação.

\section{REFERÊNCIAS}

ARAÚJO, P. C. Folhetos de cordel, uma prática educativa que motiva diálogos interculturais. Revista HISTEDBR On-line, Campinas, n.33, p.159-168, mar. 2009.

ASSIS, R. A.; et al. Literatura de cordel como fonte de informação. Pesquisa Brasileira em Ciência da Informação e Biblioteconomia, v. 7, n. 2, 2013.

GALIAZZI, M. C. Educar pela pesquisa: ambiente de formação de professores de Ciências. $2^{\text {a }}$. ed. Ijuí: Unijuí, 2011.

GUIDOTTI, C. S.; HECKLER, V. Etnopesquisa-formação com professores de ciências: uma proposição metodológica. Revista Insignare Scientia- RIS, v. 2, n. 4. Set./Dez, 2019.

LACERDA, F. G.; MENEZES NETO, G. M. Ensino e pesquisa em história: a literatura de cordel na sala de aula. Outros Tempos, v. 7, p. 217-236, 2010.

LÉVY, P. Cibercultura. São Paulo: Editora 34, 1999.

LIMA, J. M.; et al. A literatura de cordel como veículo de popularização da ciência uma intervenção no ensino de física. In: ENCONTRO NACIONAL DE PESQUISA EM EDUCAÇÃO EM CIÊNCIAS, v. 8, Campinas, 2012. Anais. São Paulo: Adaltech, 2012.

LIMA, L. G. R. C.; HAGUENAUER, C. J. Uso de ferramentas de interação em ambientes virtuais de aprendizagem. Revista Tecnologias na Educação, São Paulo, Ano 6, n. 11, 2014. 
LONGAREZI, A. M.; SILVA, J. L. Pesquisa-formação: um olhar para sua constituição conceitual e política. Revista Contrapontos, v. 13, n. 3 - p. 214-225, set-dez 2013.

LONGAREZI, A.; et al. A psicologia histórico-cultural na formação do profissional docente. Revista Série Estudos. Campo Grande: Editora da UCDB, p. 65- 78, 2007.

LUYTEN, J. O que é literatura de cordel. São Paulo: Brasiliense, 2005.

MASSETO, M. T. Mediação pedagógica e o uso da tecnologia. In: MORAN, et al. (orgs.). Novas tecnologias e mediação pedagógica. 13.ed. Campinas: Papirus, p. 133 $172,2007$.

MORAES, R. Uma tempestade de luz: a compreensão possibilitada pela análise textual discursiva. Revista Ciência e Educação, v. 9, n. 2, p. 191-211, 2003.

MORAES, R. No ponto final a clareza do ponto de interrogação inicial: a construção do objeto de uma pesquisa qualitativa. Educação, Porto Alegre, v. 25, n. 46, p. 231--248, (2002)

MORAES, R.; GALIAZZI, M. C. Análise textual discursiva. 2 ed. Ijuí: Unijuí, 2013.

MOREIRA, I. C.; et al. Cordel e a Ciência: a ciência em versos populares. Rio de Janeiro: Vieira \& Lent; Fiocruz, 2005.

PERRELLI, M. A.; et al. Percursos de um grupo de pesquisa-formação: tensões e (re)construções. Revista Brasileira de Estudos Pedagógicos, v. 94, n. 236, p.275-298, 2013.

PIMENTA, S. G.; LIMA, M. S. Estágio e docência. Rio de Janeiro: Editora Cortez, 2004

RAUSCH, R. B. Professor-pesquisador: concepções e práticas de mestres que atuam na educação básica. Revista Diálogo Educacional, Curitiba, v. 12, n. 37, p. 701-717, 2012.

SAMPIERI, R. H.; COLLADO, C. F.; LÚCIO, M. P. Metodologia de Pesquisa. 5 ed. Porto Alegre: Penso, 2013.

SANTOS, E. O. Pesquisa-formação na cibercultura. Santo Tirso: Whitebooks, 2014. 
SANTOS, E.; SILVA, I. P. A topografia da sala de aula online: reflexões a partir de uma experiência de pesquisa-formação com professores de ciências. Caderno

Brasileiro de Ensino de Física, v. 36, n. 1, p. 204-223, 2019.

SILVA, M. Criar e professorar um curso online: relato de experiência. In: SILVA, Marco. Educação online. 2. ed. São Paulo: Loyola, 2012. p. 53 - 76.

SILVA, M.; SANTOS, E. O. Conteúdos de aprendizagem na educação online: inspirarse no hipertexto. Educação \& Linguagem, São Paulo, SP, v. 12, n. 19, p. 124-142. jan./jun. 2009.

SILVA, T. T.; et al. O papel da reflexão e dos mediadores na capacitação de aprendizescolaboradores: um dos suportes andragógicos das comunidades virtuais de aprendizagem. In: VALENTE, J. A.; BUSTAMANTE, S. B. V. Educação a Distância: prática e formação do profissional reflexivo. São Paulo: Avercamp, 2009. 259 p.

TERRA, R. Memória de lutas: literatura de folhetos do Nordeste (1893-1930). São Paulo: Global Editora, 1983. 